\title{
THE ROLE OF CONCAVITY IN APPLICATIONS OF AVERY TYPE FIXED \\ POINT THEOREMS TO HIGHER ORDER DIFFERENTIAL EQUATIONS
}

\author{
Abdulmalik A. Altwaty and Paul Eloe
}

\begin{abstract}
In this article we apply an extension of an Avery type fixed point theorem to a family of boundary value problems for higher order ordinary differential equations. The theorem employs concave and convex functionals defined on a cone in a Banach space. We begin by extending a known application to a right focal boundary value problem for a second order problem to a conjugate boundary value problem for a second order problem. We then extend inductively to a two point boundary value problem for a higher order equation. Concavity of differentiable functions plays a key role in the application to second order equations. A concept of generalized concavity plays the same key role in the application to the higher order equation.
\end{abstract}

Mathematics subject classification (2010): 34B15, 34B27, 47H10.

Keywords and phrases: Boundary value problem, fixed point theorem, generalized concavity, higher order ordinary differential equation.

\section{REFERENCES}

[1] D. R. ANDERSON AND R. I. AVERy, Fixed point theorem of cone expansion and compression of functional type, J. Difference Equations Appl. 8 (2002), 1073-1083.

[2] D. R. Anderson, R. I. Avery and J. Henderson, A topological proof and extension of the Leggett-Williams fixed point theorem, Communications on Applied Nonlinear Analysis 16 (2009), 3944.

[3] D. R. Anderson, R. I. Avery and J. Henderson, Existence of a Positive Solution to a Right Focal Boundary Value Problem, Electron. J. Qual. Theory Differ. Equ. 16, 5 (2010), 6 pp.

[4] R. I. Avery, J. Henderson and D. O'Regan, Dual of the compression-expansion fixed point theorems, Fixed Point Theory and Applications 2007 (2007), Article ID 90715, 11 pages.

[5] P. Eloe And J. Henderson, Inequalities based on a generalization of concavity, Pro. Amer. Math. Soc. 125(1997), 2103-2107.

[6] R. W. Leggett AND L. R. Williams, Multiple positive fixed points of nonlinear operators on ordered Banach spaces, Indiana Univ. Math. J. 28 (1979), 673-688. 